\title{
Control of Wind Energy Conversion System and Power Quality Improvement in the Sub Rated Region Using Extremum Seeking
}

\author{
C Ganesh, S Anupama, MB Hemanth Kumar \\ Departmentof Electrical and Electronics Engineering, AITS, Rajampet India
}

\begin{abstract}
For the purpose of better utilization and to have control over varying wind speeds we use variable speed wind turbines. The performance mainly depends on the system operating point. In this paper we implement extremum seeking (ES) which is a non-model based approach for maximum power extraction in the region between cut-in speed and rated speed. The convergence of the system depends mainly on the system dynamics so we go for non-linear control based on field oriented approach and also feedback linearization. For achieving maximum power at all wind speeds the outer loop of ES is used to tune the turbine speed in the sub rated region. By adjusting the voltage magnitude and electrical frequency through matrix converter we can achieve a fast transient response. The transient response can be improved by providing inner loop control based on field oriented control. Through this we can avoid magnetic saturation in the induction generator.
\end{abstract}

Keywords: Matrix converter (MC), power generation control, Squirrel cage induction generator (SCIG), Wind energy conversion system (WECS)

\section{Introduction}

A wind turbine operates in four regions due to large moment of inertia pertaining in the rotating parts. In order to generated rated power the velocity of the wind must cross rated value, and then only it will come into operate in rated power region [1]. When the velocity of wind varies the generated power also varies proportionally i.e. turbine power and turbine speed is related to each other. But in the sub rated region the generated power is low due to low turbine speed.

In order to extract maximum power in this region, we need an optimization algorithm [2], [3], [4], [5] and when this algorithm is combined with a controller will give us desired closed loop performance as per our specifications. The generated power is a variable one due to variation in the wind speed, so while connecting this power to the grid the frequency of the existing systems must be same with the generated frequency. So we are going to connect a matrix converter in between the IG and the grid which serves as a substitute for (AC-DC-AC) circuit. This matrix converter also has bi-directional power flow capability and control of input power factor. The MC achieves MPP by regulating the voltage magnitude and electrical frequency of the stator of IG which results to variation of turbine speed.it also performs power factor correction by controlling reactive power transfer to the grid.

A similar design was proposed in [13] and it is a speed Sensorless power signal feedback algorithm. This algorithm used look up table which depends on system parameter values. The control design employs Jacobian and any kind of disturbance in the system leads the system to move away from its MPP. Some other methods were also proposed with fuzzy logic principle and four leg improved MC model presented in [6]. In this model the algorithm and controller needs to be designed again and again for each WECS.

To overcome the above problems an effective algorithm is proposed i.e. Extremum Seeking algorithm. This algorithm is a non-model based and the parameters can be varied according to our requirements. Some of these results were widely used in [7], [8], [9], [10], [11] and some designs were also shown in [2], [12]. But none of them shows interest on improving the transient response except [13]. The transient response can be improved by providing inner loop IG control based on field oriented control and the elements for this field oriented approach can be found in [14], [15]. 


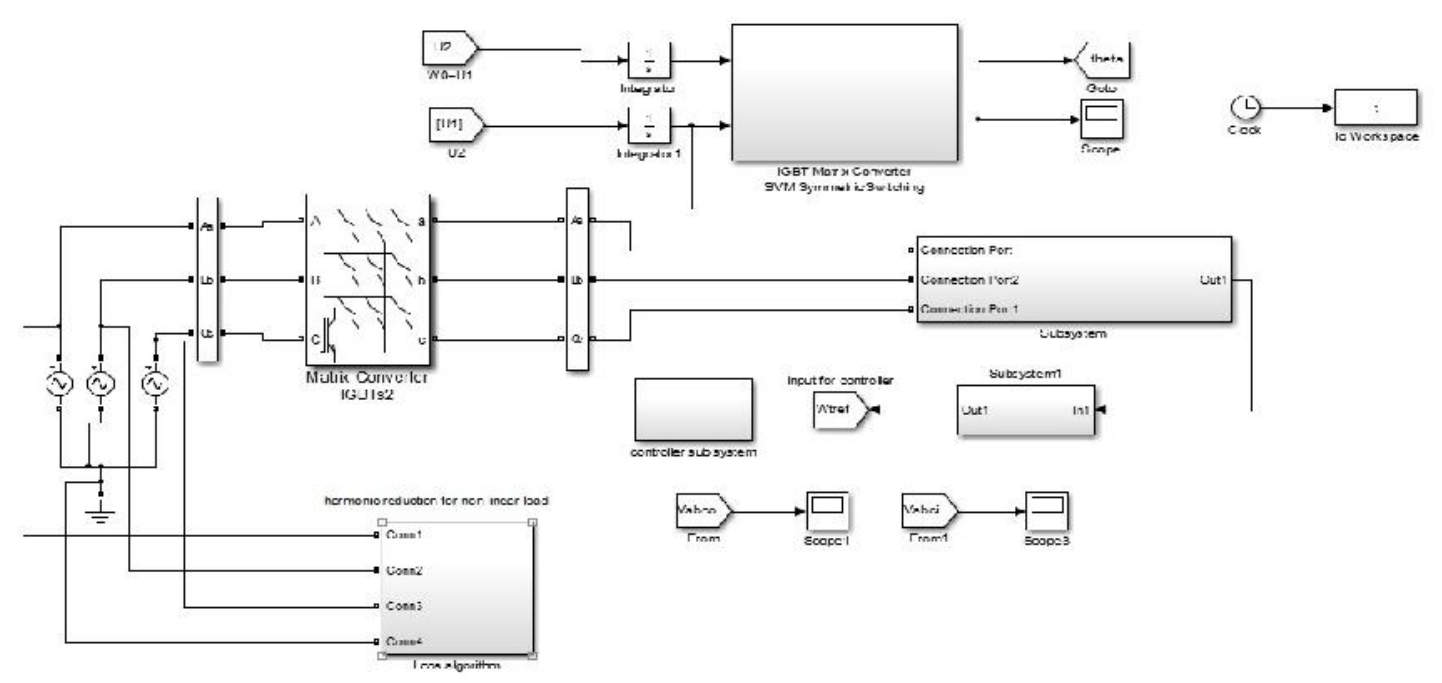

Figure 1. WECS including WT, gear box, IG and MC

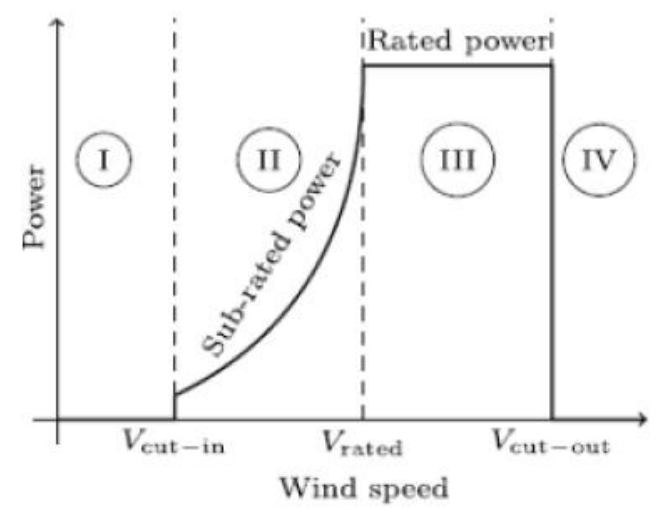

Figure 2. The typical power curve of WT indicating four operating regions

\section{Mathematical Models of WECS}

The WECS mainly consists of a variable speed wind turbine, SCIG and a MC as shown in Figure 1. A wind turbine operates in four regions and it is shown in Figure 2. When the wind speed is very low the turbine cannot generate sufficient power due to large inertia of rotating parts and this is shown in region I. When the velocity of wind gradually increases above cut in speed the generated power also increases, but it is sufficient to overcome mechanical losses and it is shown in region II, here the generated power is proportional to cube of wind velocity. In this region the machine i.e the turbine not having sufficient energy to drive the rotating parts so the alternator which is connected through this turbine is unable to generate enough power. That's the reason why the power generated in the sub-rated region is very less when compared to the power generated in the rated power region.While coming to region III the wind velocity is sufficient to produce rated output power. In the region IV due to stronger wind velocity the turbine could not withstand so it shut downs [16] there by there is no power generated in this region. Whenever the wind hits the blade area the available wind power is given by

$$
\hat{r_{w}}=\frac{1}{2} \rho A \hat{w}^{3}
$$

If we assume that blade pitch angle is zero then turbine power is give by 


$$
P_{t}=\omega_{t} T_{t}
$$

And turbine power, wind power are related as

$$
P_{t}=C_{p}\left(V_{w}, \omega_{t}\right) P_{w}
$$

Here $T_{t}$ is the rotor torque, $\omega_{t}$ is turbine speed and $C_{p}$ represents a non-dimensional power coefficient which is defined as the ratio of turbine power to wind power.

For ease of simulation the most common equation of power coefficient is given by

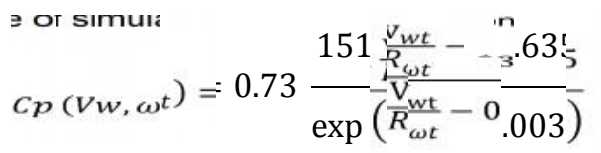

From the above equation it is clear that power coefficient depends on turbine speed and thereby we can control and optimize the power easily. The value of $C_{p}$ has been approximated numerically in [1], [23] and theoretical value is equal to 0.59 according to Betzs law. The dynamic equations for the turbine, shaft and gearbox are

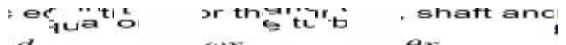

$$
\begin{aligned}
& \frac{d}{d t} \sigma=\omega t-\frac{\omega r}{P n} \cdot \sigma-\theta t-\frac{\partial r}{P n}
\end{aligned}
$$

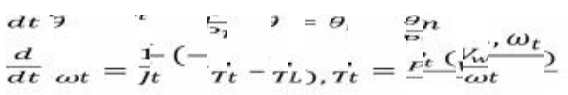

The load torque $T_{L}$ developed by the spring-damper model of the shaft is given by

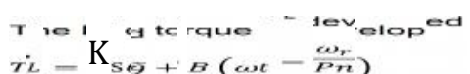

Here $\mathrm{K}_{\mathrm{s}}$ represents the stiffness coefficient of the spring and $\mathrm{B}$ is the damping ratio. By using vector control technique we can obtain fast dynamic response and accurate torque control .The $(\alpha, \beta)$ model for a SCIG is given by

$$
\begin{aligned}
& \begin{array}{l}
\beta) \quad i=1 \\
\frac{d}{d t} t \alpha=-a_{0} i_{\alpha}+a_{1} \lambda_{\alpha}+a_{2 \omega r} \lambda_{\beta}+\frac{v_{\alpha}}{\sigma \mathrm{L}_{\bar{\zeta}}}
\end{array} \\
& d t i=a i \text { a } \omega \text { o } \quad \text { os } \\
& \frac{d}{d t} \ell \beta=-{ }_{\alpha 0} \ell \beta+{ }_{a 1} \lambda_{\beta}-\mathrm{a}_{2 \omega \sigma r} \lambda_{\alpha}+\frac{v_{\bar{H}}}{\sigma \mathrm{L}_{\bar{J}}} \\
& d t^{2}-4+4= \\
& \frac{d}{d t} \lambda_{\alpha}=a_{3 t \alpha}-a_{a 4} \lambda_{\alpha}-{ }_{\omega \alpha} \lambda_{\beta} \\
& \frac{d t^{\prime \prime}}{d t} \lambda_{\beta}=d_{3} i_{\beta}-a_{4} \lambda_{\beta}-c o r i_{\alpha} \\
& d t \lambda_{1}-\mu_{i_{\beta}}-a_{1} \mu_{3}-\omega_{r} \lambda \text {. } \\
& \frac{d}{d t \omega r}=\frac{P}{T}\left(\dot{T} e-\frac{r_{L}}{n}\right)
\end{aligned}
$$

In the above equation the stator currents are denoted as $i_{\alpha}, i_{\beta}$ and rotor flux linkages as $\lambda_{\alpha}, \lambda_{\beta}$ and stator voltages as $v_{\alpha}, v_{\beta}$. The electromagnetic torque generated by IG is given by

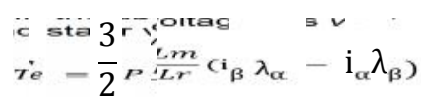


Where $L_{m}$ indicates the mutual inductance and stator inductance is given by $L_{s}=L_{1 s}+L_{m}$ and rotor inductance is given by $L_{r}=L_{l r}+L_{, m}$. The values for all these parameters are given in the appendix.

The main objective is to extract maximum power in the subrated power region. From figure 1, the matrix converter is connected between induction generator and the grid. This matrix converter serves as a substitute for back to back converter. The matrix converter mainly consists of bidirectional switches which operate in 27 different combinations. There is another advantage of $M C$ is that there is no limitation of power rating so these are the main reasons for implementing MC instead of back to back converters in between SCIG and the grid. The MC which we are using is based on the models specified in [20]. The output of induction generator is given as input for the matrix converter and it is given by

$$
\begin{aligned}
& \Rightarrow \text { inp for trie rix negrter and } 3 \text { siiven by } \\
& v_{i}=v \operatorname{im}\left(\cos \theta i \cos ^{S}\left(\theta i-\frac{2 \pi}{3}\right) \cos \left(\theta i+\frac{2 \pi}{3}\right)\right)
\end{aligned}
$$

Where $\theta_{i}$ is the input electrical angle

We know that the nature of induction generator is inductive so the output phase currents can be assumed to be sinusoidal and it is written as

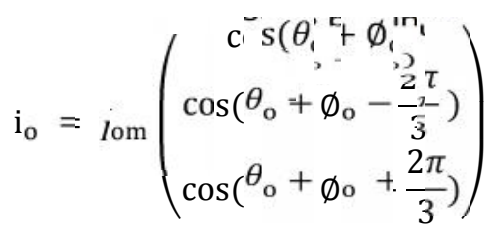

From the above expressions $V_{i m}$ and $I_{o m}$ are the peak input voltage and peak output current magnitudes, $\varnothing_{0}$ is called the load displacement angle at the output frequency, $\theta_{0}$ is the output electrical angle.

We are mainly using $\mathrm{MC}$ so that this can create average sinusoidal output phase voltage and also maintaining input phase currents also to be sinusoidal. Therefore the output phase voltage and input phase currents are given by

$$
\begin{aligned}
& \text { o age nd ink as uitreints are 'enn'by } \\
& \bar{v} O=\mathrm{O}_{\mathrm{o}}\left(\cos \theta \mathrm{o} \mathrm{c}^{\mathrm{J} \mathrm{S}}\left(\theta \mathrm{o}-\frac{2 \pi}{3}\right) \cos \left(\theta \mathrm{o}+\frac{2 \pi}{3}\right)\right) \\
& \tau_{i}=I_{\mathrm{im}}\left(\begin{array}{c}
i\left(\theta_{\mathrm{j}}-\emptyset_{\mathrm{i}}\right. \\
\cos \left(\theta_{\mathrm{i}} \neq \emptyset_{\mathrm{i}}=\frac{2 \tau}{-\frac{\tau}{3}}\right) \\
\cos \left(\theta_{\mathrm{i}}+\emptyset_{\mathrm{i}}+\frac{2 \pi}{3}\right)
\end{array}\right)
\end{aligned}
$$

From the above equations the power factor at the grid can be controlled through the input displacement angle $\varnothing_{\text {i. }}$. As the matrix converter consists of bidirectional switching devices there is a problem of modulation during the switching sequence. And this modulation problem can be overcome by finding modulation matrices such that

$$
\begin{aligned}
& \tilde{v} o=S v_{1} \\
& \tilde{i}_{\mathrm{i}}=S^{T} i_{0}
\end{aligned}
$$

The modulation problem can be overcome if the solution will satisfy a. it should be able to restrict the turn on and turn off time of the MC switches which results in preventing short circuit at the input and open circuit at the load sideb.

In order to satisfy all the above condition there are two solutions 


$$
\begin{aligned}
s^{1}= & =\frac{1}{3}\left(\begin{array}{lll}
1 & 1 & 1 \\
1 & 1 & 1
\end{array}\right)+\frac{2}{3} m T^{1}, \mathrm{~F}_{11} \text {,re } \mathrm{m}=\frac{\text { Vom }}{\text { Vim }} \\
s^{2} & =\frac{1}{3}\left(\begin{array}{lll}
1 & 1 & 1 \\
1 & 1 & 1 \\
1 & 1 & 1
\end{array}\right)+\frac{2}{3} m T^{2}, 0 \leq \mathrm{m} \leq \frac{\sqrt{3}}{2}
\end{aligned}
$$

The solution of $S_{1}$ gives same phase displacement but solution for $S_{2}$ gives opposite phase displacement. So in order to get the average of these both we combine them for better input displacement factor control as mentioned in [20] and it is given as below

$$
S=c S_{1}+(1-c) S_{2}, \quad 0 \leq c \leq 1
$$

as we are not concentrating much on power factor improvement we simply take the value of $\mathrm{c}=0.5$ to obtain a unity displacement power factor. related as

Suppose there are no losses in the MC then the input and output powers are equal and

$$
\begin{aligned}
& P^{i} \equiv \frac{3}{2} \text { vim } r i m \cos \emptyset_{1} \\
& \left.\stackrel{F}{f} \equiv \frac{3^{i}}{2} \text { b́m tom cos }\right)_{0}
\end{aligned}
$$

On solving equations we can write $l_{\text {im }}$ as

$$
i_{\mathrm{im}}=\mathrm{r}_{\mathrm{r}}{\frac{\cos \emptyset_{\mathrm{o}}}{\cos \emptyset_{\mathrm{i}}}}^{i \mathrm{om}}
$$

A system is easy to design if it is in $(\alpha, \beta)$ framework, so we transform the output voltage of IG into stationaryframe and then calculate the current being supplied to the grid with the help of stator current.

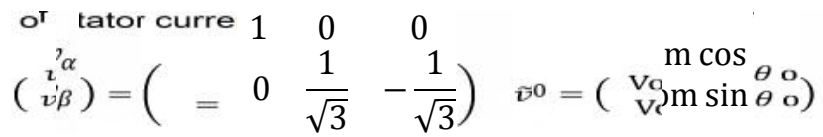

So from this output electrical angle and the output voltage magnitute can be calculated as given below

$$
\begin{aligned}
& \mathrm{V}_{\mathrm{om}}=\sqrt{v} \alpha^{2}+\bar{v} \beta^{2} \\
& v_{0}=\arctan \left(\frac{v_{0}^{\beta}}{v \alpha}\right)
\end{aligned}
$$

in a similar manner we can calculate the current supplied to the grid by using (21) where the value of $i_{0}$ is given by

$$
\mathrm{i}_{\mathrm{o}}=\left(\begin{array}{rc}
1 & 0 \\
-\frac{1}{2} & \frac{\sqrt{3}}{2} \\
-\frac{1}{2} & -\frac{\sqrt{3}}{2}
\end{array}\right)\left(\begin{array}{l}
i \alpha \\
i_{\beta}
\end{array}\right)
$$




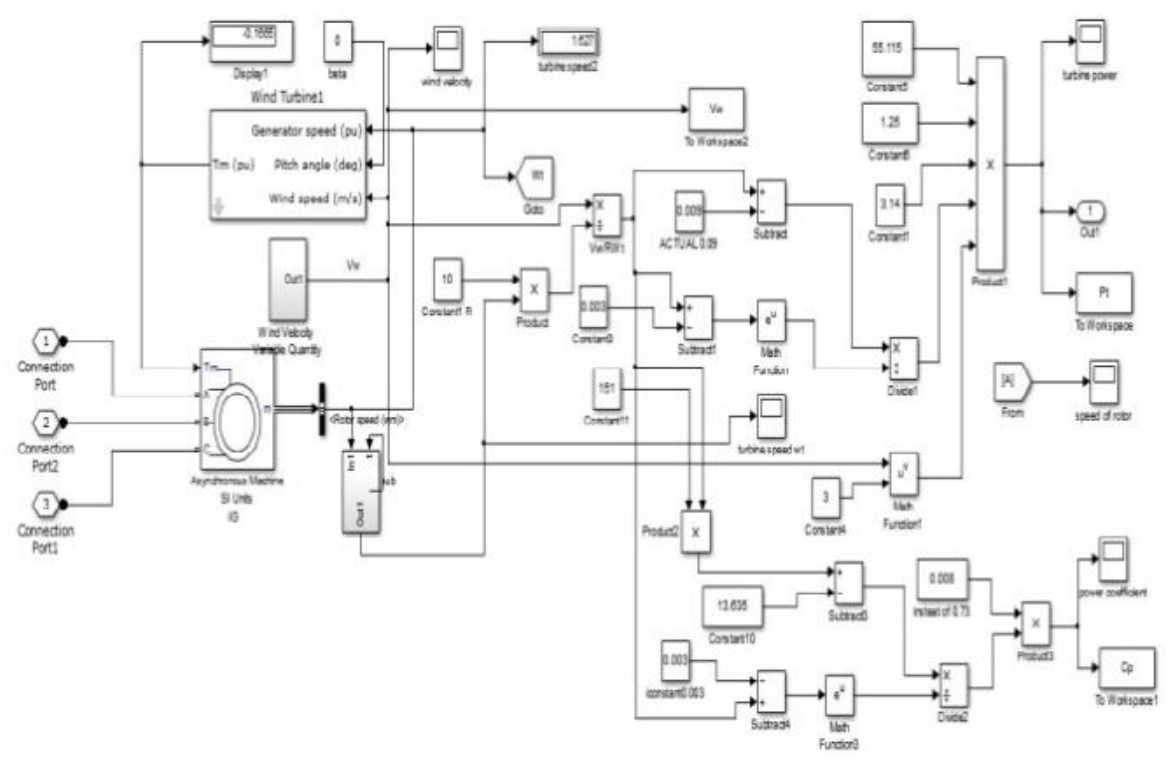

Figure 3. Simulation model of WECS

\section{Controller Design}

In order to achieve desired closed-loop performance for a WECS one must evaluate the magnitude of stator voltage and electrical frequency. From (5), (6), (8)-(12), (17) and (31) we can modify the dynamics of WECS as

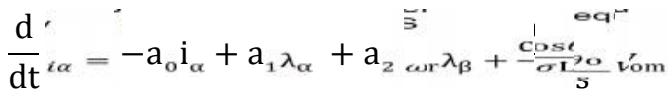

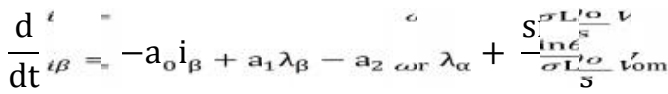

$$
\begin{aligned}
& \frac{\mathrm{d}}{\mathrm{dt}}^{i_{\kappa}}=\mathrm{a}_{3} \mathrm{i}_{\alpha}-\mathrm{a}_{4} \lambda_{\alpha}-{ }_{\omega r}^{\mathrm{a}} \lambda_{\beta} \\
& \frac{\mathrm{d}}{\mathrm{dt}}^{\lambda \beta}=\mathrm{a}_{3} \mathrm{i}_{\beta}-\mathrm{a}_{4} \lambda_{\beta-}-{ }_{\omega r} \lambda_{\alpha} \\
& \frac{\mathrm{d}}{\mathrm{dt}}^{\lambda{ }^{\lambda}}=\omega_{\mathrm{o}}
\end{aligned}
$$

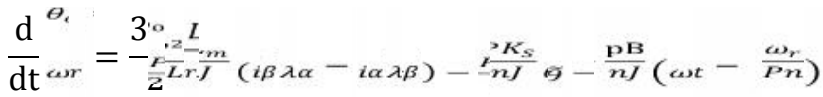

$$
\begin{aligned}
& \text { dt } \omega_{r}=\overline{z L_{r}} \cdot \cdots \cdot \ldots \\
& \frac{d}{d t} \sigma-\omega t-\frac{\omega r}{P r}
\end{aligned}
$$

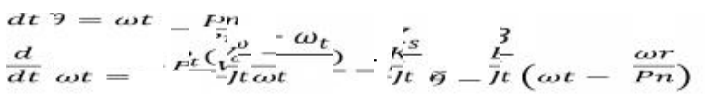

In the above equation $\omega_{0}$ and $V_{\mathrm{om}}$ are the actuated quantities from MC. The variable quantity is the $V_{\omega}$, which will determine MPP of the WT. The simulation model of WECS consisting of state-space model for the above equations is as shown in Figure 3. By introducing a one-step integration for $\mathrm{V}_{\text {om }}$ the equations for WECS can be written as follows 


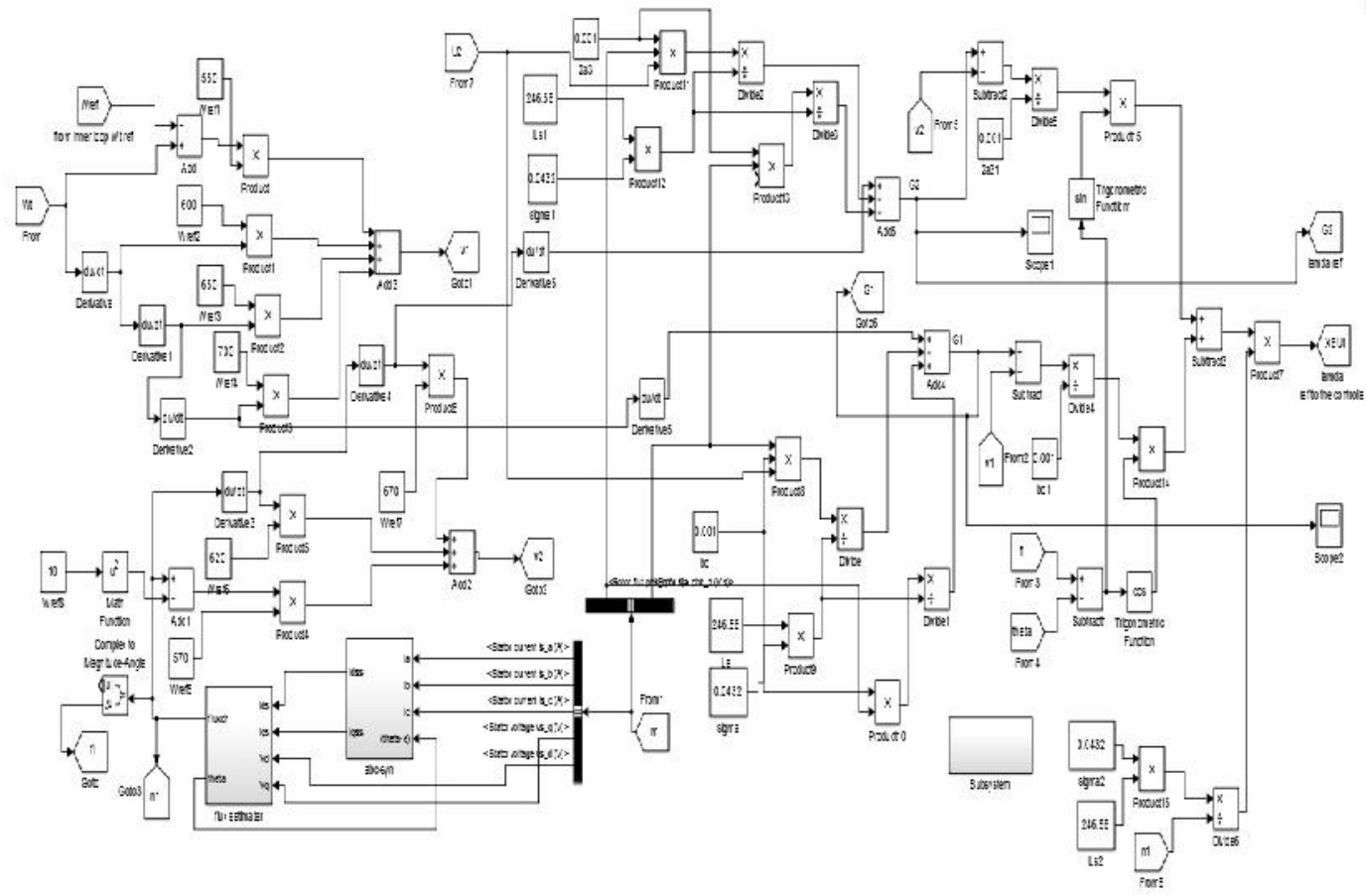

Figure 4. ES for MPPT in WECS with inner loop control

\section{Extremum Seeking}

There are various techniques for obtaining MPPT among them three main techniques are wind speed measurement, perturbation and observation, power signal feedback method. The measurement of wind velocity is complicated and increases the cost of the system.

The perturbation and observation adds delay so it is not practical for medium and large inertia wind turbine systems.in order to implement PSF maximum power and turbine speed characteristics is required.In this ES scheme we consider the mechanical power available at the rotor of the SCIG as the cost function and angular velocity of wind speed as the optimization parameter.

The ESalgorithm will estimate the optimal speed of the turbine which is considered as a constant value with varying system dynamics. This scheme also estimates the gradient of the cost functionby introducing a small step changes in the form of a $\sin \left(\Omega_{\mathrm{t}}\right)$. When this signal is being multiplied with $\sin (\Omega t)$ it will estimate the gradient of cost function, this can be further smoothened by using a low- pass filter. 


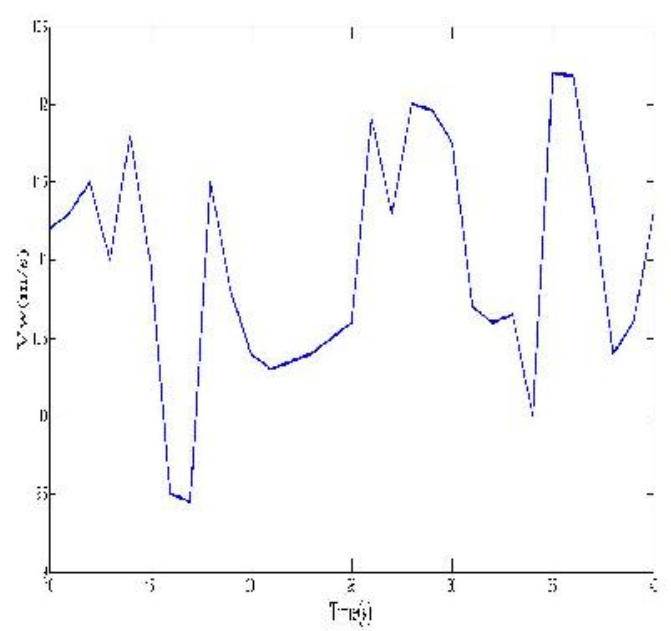

Figure 5 . Variation of wind velocity with time

The closed-loop system for the ES design in which the dynamics of $\dot{\varphi}$ can be neglected without hurting the proof. The ES scheme is shown in Figure 4. Combinationof inner loop Controller and WECS.it has been already mentioned that the ES without inner loop is comparatively slow a leads to low power efficiency with respect to ES with inner loop. Here we compare the simulation of the design without inner loop with the proposed algorithm which reveals the importance of inner loop. The variation of wind velocity with time is shown in Figure 5.

\section{Simulation Results}

By properly selecting the appropriate feedback gains the desired closed loop response time is obtained. The response time is about for this closed loop system is about $20 \mathrm{~ms}$, which is 25 times faster than the open loop system. The parameters being selected for the ES loop are: $\Omega=100 \mathrm{rad} / \mathrm{s}, \Omega_{L}=6 \mathrm{rad} / \mathrm{s}, \Omega_{H}=5 \mathrm{rad} / \mathrm{s}, a=0.1$, and $k=0.004$. Higher the value of $a$ reduce the precision of the MPPT.

The process of getting MPPT is shown in Figure 6 and by implementing this ES algorithm, the value of power coefficient stays close to $C_{p}^{*}$ at fast varying wind speeds and it is shown in Figure 7.

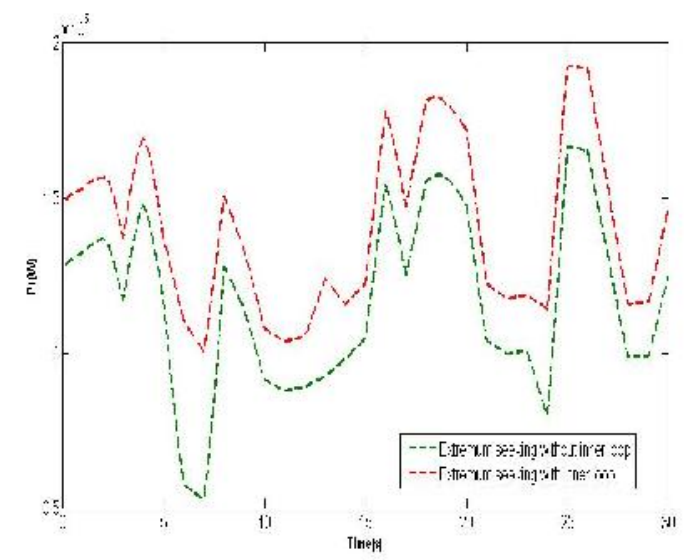

Figure 6. MPPT, (solid red line) our proposed algorithm, (solid blue line) ES without inner loop 


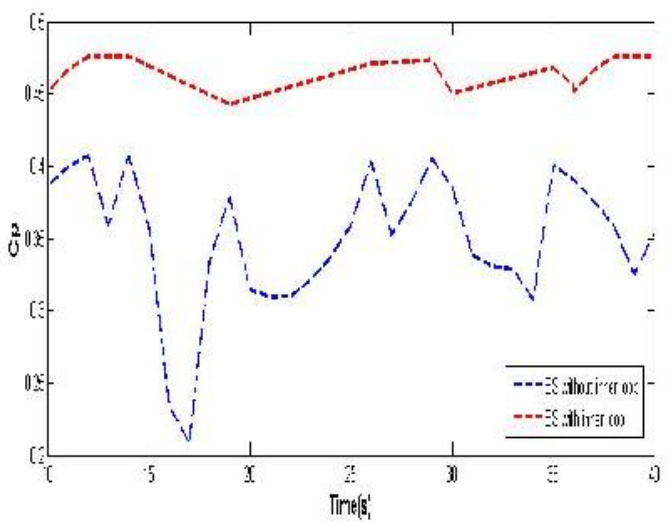

Figure 7. Variation of power coefficient, (solid red line) our proposed algorithm, (solid blue line) ES without inner loop

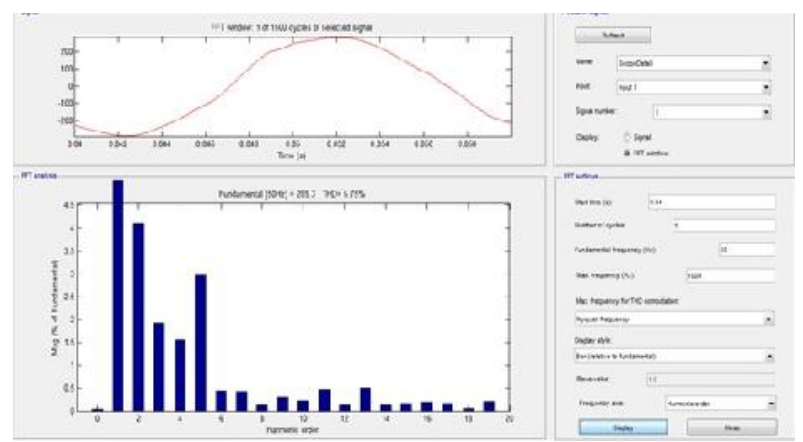

Figure 7. THD improvement for the non-linear load by using I-Cos $\varnothing$ algorithm

Sometimes the system may experience the nature of non-linear loads and at that condition the system must be in a situation to meet the undesirable conditions so that the system may not underperform at that situation.

We design the shunt active filter for the non-linear load by using the I-Cos $\varnothing$ algorithm by which the harmonic distortion gets reduced and the system performance gets improved in a better way. Figure 7 shows the improvement of power quality for a non linear load when it is connected to the system bus.

\section{Conclusion}

The main objective of this paper is achieved by implementing ES algorithm for extracting maximum power in the region lying between cut-in speeds to rated speed. The ES design mainly consisting of inner loop non-linear controller based on field oriented approach and also linearization for improving transient performance, by this the ES is to be tuned. This ES algorithm can be easily extended for other applications also without major changes. In this one the two important parameters that need to be adjusted are the amplitude of perturbing signal and the frequency. This proposed control also prevents magnetic saturation of the IG.

\section{References}

[1] PM Anderson and A Bose. "Stability simulation of wind turbine systems". IEEE Trans. Power App. Syst. 1983; 102(12): 3791-3795.

[2] Al Bratcu, EC lulian Munteanu and S Epure. "Energetic optimizationof variable speed wind energy conversion systems by extremumseeking control'. in Proc. Int. Conf. Comput. Tool. 2007: 25362541. 
[3] SMR Kazmi, H Goto, HJ Guo and O Ichinokura. "A novelalgorithm for fast and efficient speedsensorless maximum power pointtracking in wind energy conversion systems". IEEE Trans. Ind. Electron. 2011; 58(1): 29-36.

[4] T Pan, Z Ji and Z Jiang. "Maximum power point tracking of windenergy conversion systems based on sliding mode extremum seekingcontrol'. in Proc. IEEE Energy Conf. 2008: 1-5.

[5] T Senjyu, R Sakamoto, N Urasaki, T Funabashi, H Fujita, and H Sekine. "Output power leveling of wind turbine generator for alloperating regions by pitch angle control". IEEE Trans. Energy Convers. 2006; 21(2): 467-475.

[6] V Kumar, RR Joshi and RC Bansal. "Optimal control of matrixconverter-based WECS for performance enhancement and efficiencyoptimization". IEEE Trans. Energy Convers. 2009; 24(1): 264-273.

[7] $\mathrm{R}$ Becker, $\mathrm{R}$ King, $\mathrm{R}$ Petz and $\mathrm{W}$ Nitsche. "Adaptive closed-loop separation control on a high-lift configuration using extremum seeking". AIAA J. 2007; 45(6): 1382-1392.

[8] D Carnevale, A Astolfi, C Centioli, S Podda, V Vitale and L Zaccarian. "A new extremum seeking technique and its applicationto maximize RF heating on FTU". Fusion Eng. Des. 2009; 84: 554-558.

[9] M Guay, M Perrier and D Dochain. "Adaptive extremum seeking control of nonisothermal continuous stirred reactors". Chem. Eng. Sci. 2005; 60(13): 3671-3681.

[10] N Killingsworth and M Krsti'c. "Auto-tuning of PID controllers via extremum seeking". in Proc. Amer. Control Conf. 2005; 4: 2251-2256.

[11] L Luo and E Schuster. "Mixing enhancement in 2D magnetohydrodynamic channel flow by extremum seeking boundary control'. in Proc. Amer. Control Conf. 2009: 1530-1535.

[12] M Komatsu, H Miyamoto, H Ohmori and A Sano. "Output maximization control of wind turbine based on extremum control strategy". in Proc. Amer. Control Conf. 2001: 1739-1740.

[13] SM Barakati, M Kazerani and JD Aplevich. "Maximum power tracking control for a wind turbine system including a matrix converter". IEEE Trans. Energy Convers. 2009; 24(3): 705-713.

[14] AD Luca and G Ulivi. "Dynamic decoupling of voltage frequency controlled induction motors". in Proc. 8th Int. Conf Anal. Optim. Syst. 1988: 127-137.

[15] R Marino, S Peresada and P Valigi. "Adaptive input-otput linearizing control of induction motors". IEEE Trans. Autom. Control. 1993; 38(2): 208-221.

[16] SJ Johnson and CPC van Dam. "Active load control techniques for wind turbines". Sandia Nat. Lab., Albuquerque, NM, USA, Tech Rep. SAND2008-4809. 2008.

[17] M Krsti'c and HH Wang. "Stability of extremum seeking feedback for general nonlinear dynamic systems". Automatica. 2000; 36(4): 595-601. 